\title{
FAO and the Situation of Food Security and Nutrition in the World
}

\author{
Mbuli Charles BoLIKO \\ Liaison Office in Japan, Food and Agriculture Organization of the United Nations, Yokohama, Japan
}

\begin{abstract}
Summary New evidence shows that the number of hungry people in the world is growing, reaching more than 820 million in 2018 (one in every nine people), up from 812 million in 2017. There are three main causes of food insecurity: high exposure and vulnerability to climate extremes, conflicts, and economic slowdown. Paradoxically, every year, roughly one third of the food produced in the world for human consumption-approximately 1.3 billion tonnes-is lost or wasted. It is estimated that, if the food lost or wasted globally could be reduced by just one quarter, this would be sufficient to feed the people suffering from chronic hunger in the world. Rice, an important staple food for over half the world's population, is also affected. At the same time, evidence shows that the food lost or wasted is a major cause of greenhouse gas emission, which itself feeds into climate change and extreme weather, resulting in further food insecurity and malnutrition. This paper briefly introduces the Food and Agriculture Organization of the United Nations (FAO), presents the recent findings on the current situation of food security and nutrition in the world, and highlights the issue of food loss and waste and its impact on food security, with particular emphasis on the constraints it poses to the achievement of key Sustainable Development Goals (SDGs).
\end{abstract}

Key Words food, agriculture, food security, nutrition, food loss and waste (FLW), Sustainable Development Goals (SDGs)

\section{About FAO}

The Food and Agriculture Organization of the United Nations (FAO) was established on 16 October 1945, with the mission of achieving food security for all by making sure that people have regular access to enough high-quality food to lead active, healthy lives. FAO's mandate is to raise levels of nutrition, improve agricultural productivity, better the lives of rural populations and contribute to the growth of the world economy.

As a knowledge organization, FAO generates and shares updated information to ensure sustainable food production in all areas, including agriculture, fisheries and aquaculture, animal production and health, forestry, and natural resource management.

In remembrance of the founding date of the Organization, member countries agreed, at the 20th FAO Conference in November 1979, to institute the World Food Day (WFD) on 16 October each year. Since then, WFD is celebrated worldwide, with the objective of raising awareness of the issues behind poverty and hunger.

\section{Food Security and Nutrition in the World}

The latest issue of The State of Food Security and Nutrition in the World 2019 (SOFI 2019) was published by FAO in July 2019, in collaboration with the International Fund for Agricultural Development (IFAD), the United Nations Children's Fund (UNICEF), the World Food Programme (WFP) and the World Health Organization (WHO). This FAO flagship publication provides new evidence, as shown in Fig. 1, that the number of hungry people in the world has been growing over the last three

E-mail: MbuliCharles.Boliko@fao.or years, reaching more than 820 million in 2018, that is, one in every nine people. The number of people who suffer from chronic hunger has thus returned to levels from a decade ago.

Limited progress is also being made in addressing the multiple forms of malnutrition, ranging from child stunting to adult obesity, putting the health of hundreds of millions of people at risk.

Some of the facts around the global hunger are as follows:

$>$ Worldwide, enough food is produced to feed everyone, yet this food and the technology to produce it do not always reach those in need.

$>$ Asia has the largest number of people living in food insecurity - 513.9 million, or two thirds of the total.

$>$ East Africa has the largest proportion of people living in food insecurity, that is, one in three people.

$>$ Hunger kills more people every year than malaria, tuberculosis and HIV-AIDS combined.

$>$ Around $45 \%$ of infant deaths are related to malnutrition.

$>$ Malnutrition costs the global economy the equivalent of USD 3.5 trillion a year.

Ironically, obesity is rising everywhere at an accelerating pace, and more than one in eight adults in the world is obese. The problem is most significant in North America, but Africa and Asia are also experiencing an upward trend, according to SOFI 2019. Undernutrition and obesity coexist in many countries, and can even be seen side by side in the same household.

\section{Causes of Food Insecurity}

The State of Food Security and Nutrition in the World 
17 1237

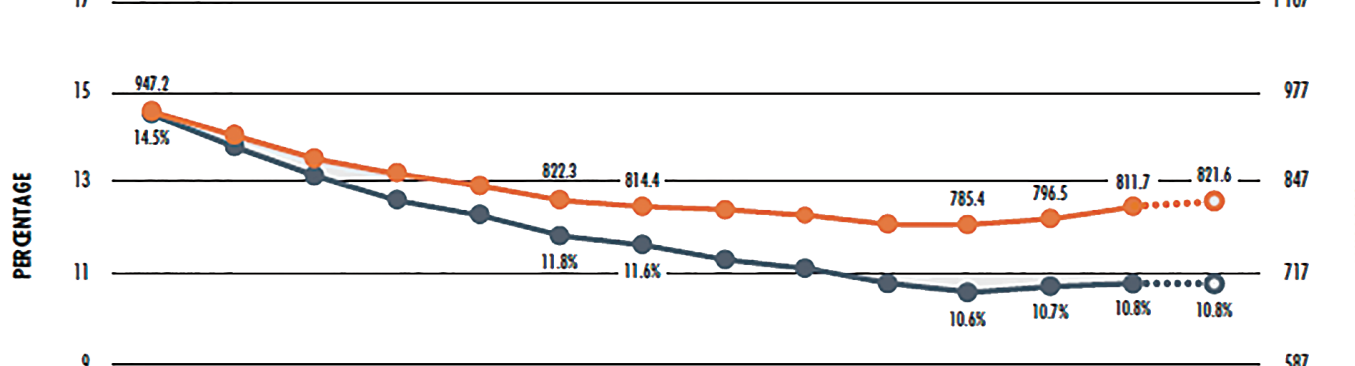

\section{7}

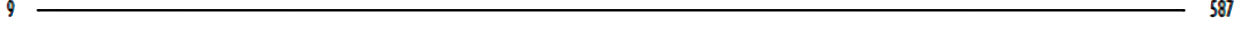

457

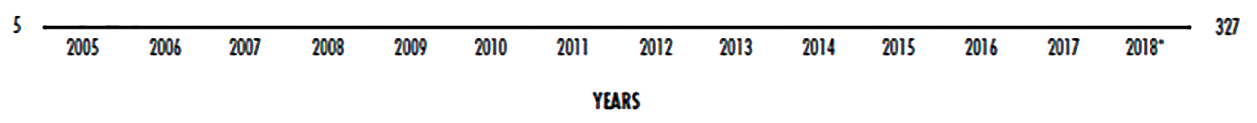

YEARS

$\Longrightarrow$ Prevalence of undernourishment (percentage) $\quad \Longrightarrow$ Number of undernourished (millions)

Fig. 1. The number of undernourished people in the workd has been on the rise since 2015 and is back to levels seen in 2010-2011.

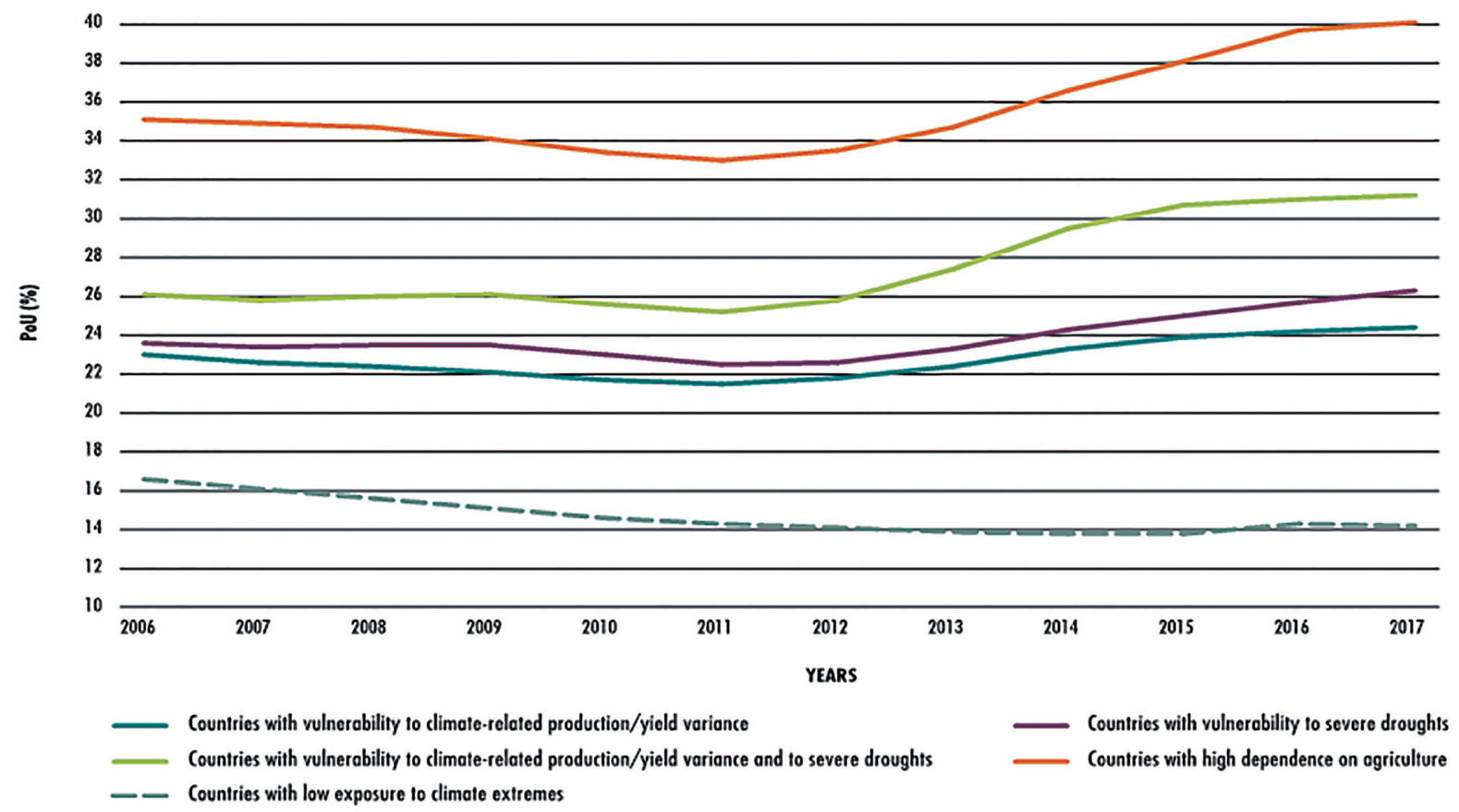

Fig. 2. Undernourishment is higher for countries with both exposure to climate extremes and high vulnerability.

2018 (SOFI 2018) highlights three main causes of the current rise in food insecurity: climate variability and extremes, conflict, and economic slowdown.

i. High exposure and vulnerability to climate extremes

Climate variability and extremes are a rising trend, not only in terms of frequency, but also in terms of multiple different types of climate extremes to which countries are exposed.
As shown in Fig. 2, the increase in the prevalence of undernourishment $(\mathrm{PoU})^{\mathrm{i}}$ is more pronounced for those countries with both high exposure to climate extremes and high levels of vulnerability. Countries highly dependent on agriculture show the highest levels of PoU, whereas countries experiencing both climate-sensitive vulnerability of production/yields and vulnerability to severe drought show the sharpest increase in under-

${ }^{\mathrm{i}}$ The prevalence of undernourishment (PoU) is the traditional FAO indicator used to monitor hunger at the global and regional level. It is described in detail in the publication “The State of Food Security and Nutrition in the World 2018” (FAO, 2018). 


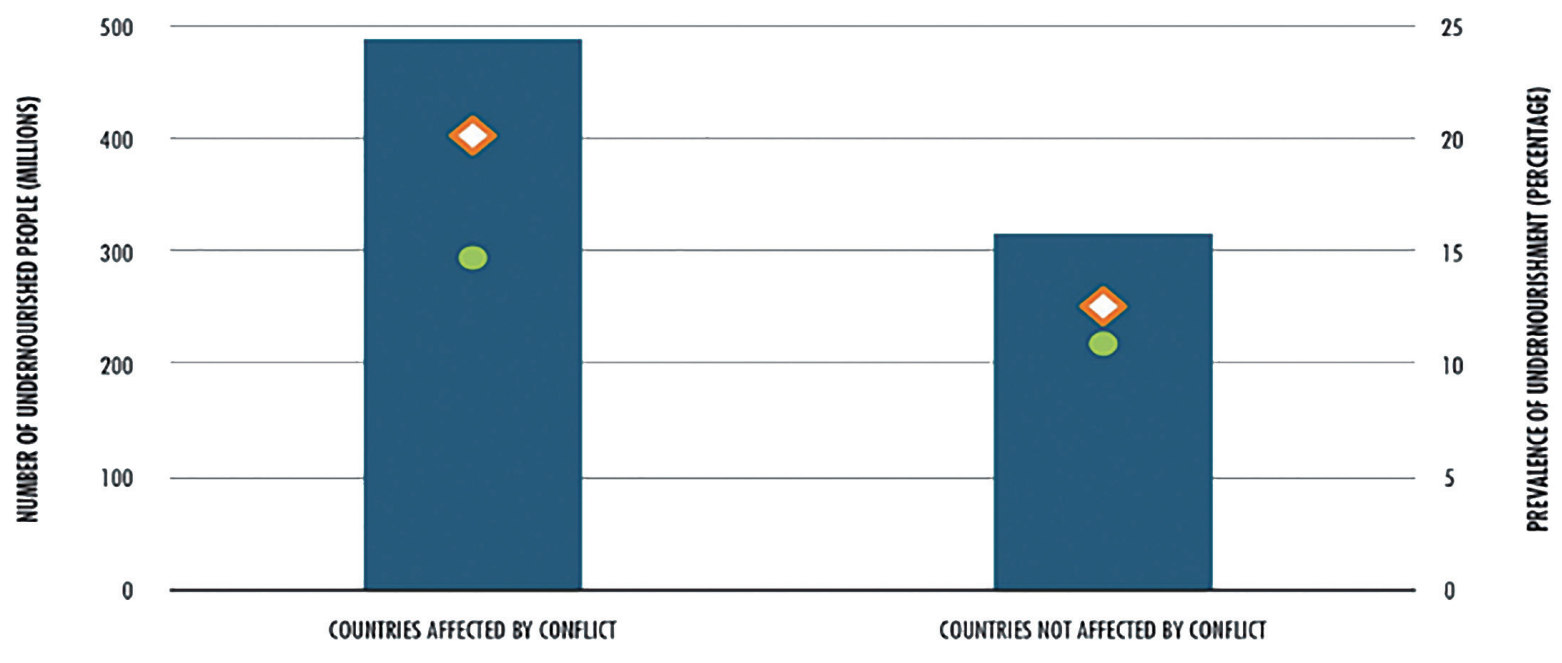

Fig. 3. Highest levels of food insecurity and undernutrition are in countries in conflict.

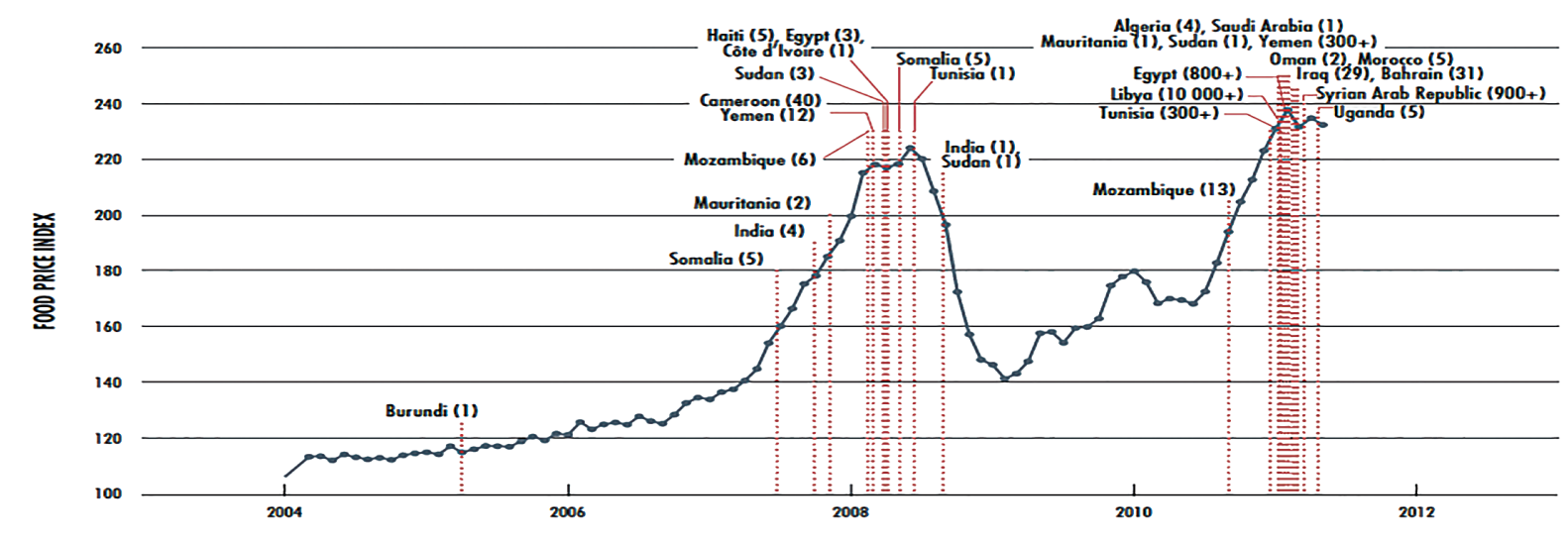

NOTES: Time dependence of FAO Food Price Index from January 2004 to May 2011. Red dotted vertical lines correspond to beginning dates of "food riots" and protests associated with the major recent unrest in North Africa and the Near East. Overall death toll in parentheses. Price data are FAO Food Price Index from 2004 to 2011 Cambridge, USA, New England Complex Systems Institute.

Fig. 4. Food price increases and conflicts.

nourishment starting from 2011, followed by countries with either production/yield vulnerability or vulnerability to severe drought.

In contrast, Fig. 2 further shows a PoU reduction during the same period in countries that are less vulnerable to extreme weather conditions. This confirms that vulnerability to climate change is a major cause of food insecurity.

\section{ii. Conflicts}

Figure 3 shows that highest levels of food insecurity and undernutrition are found in countries in conflict. According to the the State of Food Security and Nutrition in the World 2017 (SOFI 2017), simple correlations show higher levels of chronic and acute food insecurity and undernutrition in countries affected by conflict. In 2016, the unweighted average of the PoU in countries affected by conflict was almost eight percentage points higher than countries not affected by conflict.

Conflict is a key driver of severe food crisis and recently re-emerged famines, while hunger and undernutrition are significantly worse where conflicts are prolonged and institutional capacities weak.

It is worth mentioning that, on 24 May 2018, the United Nations Security Council, in acknowledgment of the above findings, unanimously adopted its first-ever resolution recognizing the link between armed conflict and food insecurity, and condemning the starving of civilians as a method of warfare. The resolution further calls on all parties to armed conflict to comply with their obligations under international humanitarian law regarding the protection of civilians and on taking care to spare civilian objects, stressing that armed conflicts, violations of international law and related food insecurity could be drivers of forced displacement.

While conflict leads to food insecurity, there is also evidence that insufficient access to food may lead to riots and social unrest. As illustrated in Fig. 4, by limiting people's access to food, the sharp increases in food prices observed around 2008 and 2011 resulted in serious unrest even in countries that are traditionally peaceful. 
Total GHGs emissions excluding LULUCF

Top 20 of countries (year 2011) vs. Food wastage

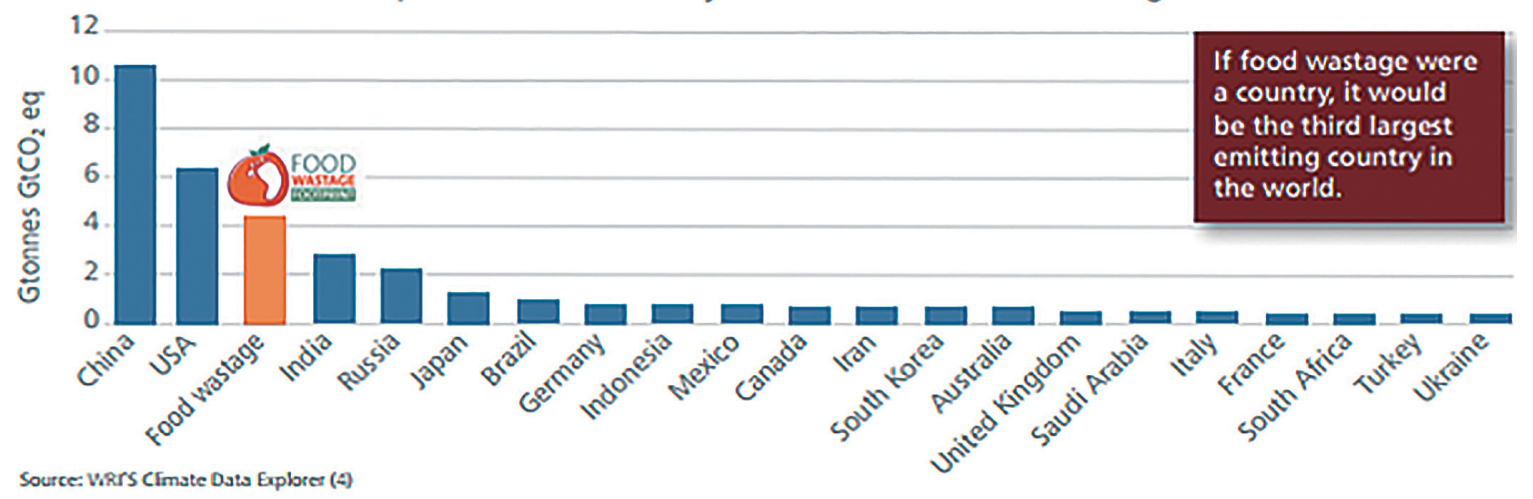

Fig. 5. Food loss and waste are a major source of greenhouse gas.

In countries with lower levels of resilience, social unrest can occur even with slight increases in food prices, as was the case in Burundi in 2005.

iii. Economic slowdown

Worsening food security conditions have also been observed in more peaceful settings, especially where economic slowdown has drained foreign exchange and fiscal revenues. This affects both food availability through reduced import capacity, and food access through reduced fiscal space to protect poor households against rising domestic food prices. According to SOFI 2019, 65 out of 77 countries that experienced the rise in undernourishment between 2011 and 2017 simoultaneously suffered economic slowdowns or downturns.

Economic inequalities are also associated with food insecurity and malnutrition. Income inequality increases the likelihood of severe food insecurity, and this effect is 20 percent higher for low-income countries compared with middle-income countries.

\section{SDGs and Food Security}

On 25 September 2015, the 193 Member States of the United Nations adopted the 2030 Agenda for Sustainable Development, with its 17 Sustainable Development Goals (SDGs) that are expected to guide the actions of the international community for a period of $15 \mathrm{y}$ (2016-2030). To track progress in the achievement of the 17 goals, the new Agenda includes 169 targets and 232 indicators.

The 2030 Agenda offers a vision of a fairer, more peaceful world in which no one is left behind. Food and agriculture are key to achieving multiple SDGs. Accordingly, FAO is the custodian UN agency for 21 SDG indicators (i.e. nearly 10 percent of the total number of SDG indicators) across five SDGs (SDGs 2, 5, 6, 12, 14 and 15 ), and is a contributing agency for many other indicators. Virtually every SDG is linked to the work of FAO, an institution that has restructured itself over the last several years in order to better support countries' efforts in monitoring progress and achieving the 2030 Agenda.

As explained earlier, the issue of FLW constitutes a major constraint in achieving food security for all.
According to studies conducted by FAO in 2011, every year, roughly one third of the food produced in the world for human consumption-approximately 1.3 billion tonnes - gets lost or wasted. Global quantitative food losses and waste per year are roughly $40-50 \%$ for root crops, fruits and vegetables; $35 \%$ for fish and seafoods; $30 \%$ for cereals; and $20 \%$ for oil seeds, meat and dairy products. Per capita waste by consumers is between 95-115 kg a year in Europe and North America, while in sub-Saharan Africa, south and south-eastern Asia, it stands only at $6-11 \mathrm{~kg}$. In developing countries, $40 \%$ of losses occur at post-harvest and processing levels, especially due to poor infrastructure; in industrialized countries, more than $40 \%$ of wastage happens at retail and consumer levels.

For the purpose of this article, the following three SDGs are particularly relevant to FLW:

\section{i. SDG2-Zero Hunger}

It is estimated that, if the food wasted or lost globally could be reduced by just one quarter, this would be sufficient to feed all the people suffering from chronic hunger globally.

Food losses represent a waste of resources used in production such as human time and effort, land, water, energy and other inputs such as seeds, fertilizers and the like. It is sufficiently compelling to note, for example, that the current food production systems allow the use of land that is larger than the territory of China to produce food that no one will ever eat. This leads to the staggering loss of some 2.6 trillion US dollars to the world economy. This is arguably unsustainable.

ii. SDG 12-Responsible Consumption and Production

In view of the above information, all member countries of the United Nations, in adopting the 2030 Agenda, agreed to halve per capita global food waste at the retail and consumer levels and reduce food losses along production and supply chains, including postharvest losses, by 2030.

It is therefore the responsibility of everyone, public as well as private institutions, producers as well as consumers, groups as well as individuals, to reconsider their beliefs, policies, procedures and practices, to ensure that 
this target is reached in the interest of all.

iii. SDG 13-Climate Action

Figure 5 provides data demonstrating that, if food wastage were a country, it would be the third largest greenhouse gas (GHG) emitting country in the world, after China and the United States of America. It should also be noted that the amount of $\mathrm{CO}_{2}$ emanating from food lost at the agricultural production level is significantly lower than that generated by food waste at the consumer level. This suggests that a change of behavior among consumers is likely to have greater impact in reducing GHG emissions.

Given the impact of GHG in global warming and extreme weather conditions, and the resulting destructions in infrastructure and means of production, in particular in the agriculture sector, it is imperative that measures be taken at all levels to reduce FLW.

\section{Conclusion}

It is not acceptable that, in a world that produces enough food, one in nine people continues to go hungry, with dramatic consequences on human health and the world economy. The situation is even more egregious considering that significant resources are spent to produce food that ends up in garbage, thus undermining the very existence of humans on the planet through climate change and extreme weather conditions.

Rice, a staple food for over half the world's population, and a crop of proven nutritional, cultural and economic importance worldwide, is also affected by both FLW and the scourge of climate change, the latter being likely to negatively affect yields in a significant way.

SDGs have been adopted to ensure that no one is left behind. They provide a framework for Partnerships that must shape policies and actions to ensure Prosperity for all People while caring for the Planet and maintaining the world Peace. The five Ps call for both inclusiveness and interdependence.

Establishing effective food value chains that prevent unnecessary food wastage, facilitate access to nutritious food by the most vulnerable, improve rural development and contribute to the world economy, is essential if SDGs are to be achieved.

\section{Disclosure of State of COI}

No conflicts of interest to be declared.

\section{Acknowledgments}

This article summarizes the presentation made at the Third International Symposium on Rice Science in Global Health, which took place on 29 and 30 November 2018 in Kyoto, Japan. The author would like to express his gratitude to the organizers for the precious opportunity to intervene as a keynote speaker on behalf of FAO, and also to learn so much from the many brilliant scientists who shared their research findings.

\section{REFERENCES}

1) FAO: http://www.fao.org/home/en/

2) FAO. 2019. The State of Food Security and Nutrition in the World 2019. http://www.fao.org/3/ca5162en/ ca5162en.pdf

3) FAO. 2018. The State of Food Security and Nutrition in the World 2018. http://www.fao.org/3/I9553EN/ i9553en.pdf

4) FAO. 2017. The State of Food Security and Nutrition in the World 2017. http://www.fao.org/3/a-I7695e.pdf

5) FAO. 2017. FAO's Work on Climate Change. http://www. fao.org/3/a-i8037e.pdf

6) FAO. 2016. Greenhouse Gas Emissions from Agriculture, Forestry and Other Land Use. http://www.fao. org/3/a-i6340e.pdf

7) FAO: [YEAR?] Food wastage footprint \& Climate Change. http://www.fao.org/3/a-bb144e.pdf

8) IFAD: https://www.ifad.org/en/about

9) United Nations Meetings Coverage and Press Releases, SC/13354, 24 May 2018. https://www.un.org/press/ en/2018/sc13354.doc.htm

10) World Food Programme: http://www1.wfp.org/ 